To cite: Wolfe, Joseph D. and Mieke Beth Thomeer. Forthcoming. "Divorce, Economic Resources, and Survival Among Older Black and White Women." Journal of Marriage and Family.

JoSEPH D. WOLFE

MieKe Beth ThOMEer
University of Alabama at Birmingham

University of Alabama at Birmingham

\title{
Divorce, Economic Resources, and Survival among Older Black and White Women
}

Objective: This study identifies which midlife economic resources reduce the association between divorce and mortality risk among older Black and White women.

Background: Despite evidence that divorce increases mortality risk due to economic losses, research has not established which among several common economic resources related to divorce are most important for older women's survival. There is also relatively little research on why marital inequalities in mortality are smaller among older Black women. Drawing from diverse areas of scholarship, we hypothesize that group differences in multiple economic resources explain this finding.

Method: Fractional logistic regression and Gompertz proportional hazards models were estimated with data from the NLS-MW $(N=4,668$; nlsinfo.org) to examine the associations between divorce, economic resources, and mortality among older Black and White women (born 19231937).

Results: Divorced White women had significantly less housing and financial wealth than their continuously married counterparts, and Both
Black and White divorcées had less vehicle wealth and higher probabilities of indebtedness. With respect to survival, net worth and housing wealth accounted for the largest reductions in marital and racial differences in survival.

Conclusion: Findings suggest that wealth-home wealth in particular - is key to understanding the greater longevity of married White women compared to Black women and divorced White women. Interventions aimed at reducing health disparities must first address the social practices creating economic inequalities.

Divorced adults generally have shorter life expectancies than their married counterparts (Liu 2009, Rendall, Weden et al. 2011, Sbarra, Law et al. 2011), and a large body of multidisciplinary research has made progress in identifying the specific behavioral, psychological, and biological mechanisms that help explain the association between divorce and mortality risk (e.g., Whisman, Robustelli et al. 2016, Malgaroli, Galatzer-Levy et al. 2017, Bourassa, Ruiz et al. 2019). However, a frequently proposed explanation-divorce leads to steep declines in economic resources (Smock 1993, Smock 1994, 
Addo and Lichter 2013, Tach and Eads 2015) that negatively impact longevity (Duncan, Daly et al. 2002, Pool, Burgard et al. 2018) — has received relatively little attention. Moreover, the limited research in this area only considers income and net worth (e.g., Lillard and Waite 1995, Dupre, Beck et al. 2009, Liu, Umberson et al. 2020) and does not assess the larger array of common economic resources that are often reduced by divorce.

A closer examination of economic resources may also shed light on why past studies often observe racial differences in the outcomes of marital disruption (Liu and Reczek 2012, Addo and Lichter 2013, Dupre 2016). Race and racism are critical to understanding the economic and healthrelated correlates of divorce in the U.S., especially among older adults. In the early to mid-twentieth century, when marriage was often seen as the most viable path to financial stability among young, White women who had limited labor force options (Holden and Smock 1991), Black families were systematically blocked from building wealth through traditional pathways like homeownership (Keister 2004, Woldoff and Ovadia 2009). This lack of an economic pay-off from marriage could help explain why marital inequalities in mortality are smaller among older Black populations (Dupre 2016, Liu, Umberson et al. 2020, Umberson and Thomeer 2020). Another possibility is that divorce and mortality among Black women are linked by economic resources that avoid institutionalized gatekeepers such as banks (Addo and Lichter 2013, Wolfe, Baker et al. 2019). Yet, existing research does not disaggregate income and wealth to the extent necessary to observe these potential explanations of racial differences.

These gaps in research represent important pieces of missing information on marital inequalities in mortality risk among older women. To address these gaps, we investigate two questions: (1) What specific economic resources reduce the association between divorce and mortality risk among older women? (2) Do these resources differ for Black and White women? To answer these questions, we use data from the National Longitudinal Survey of Mature Women
(NLS-MW). The NLS-MW began in 1967 with a nationally representative sample of adult women between the ages of 30 and 44 and continued data collection until 2003. In addition to over 30 years of detailed information on women's marital status and economic resources, the NLS-MW includes age of death for women who died by 2012, making these data optimal for answering our research questions.

We begin below by reviewing scholarship connecting marriage, divorce, economic resources, and mortality risk. Next, because the historical period in which a person is born determines the social meaning and consequences of life course events such as marriage and divorce (Elder and George 2016), we develop hypotheses in light of the socio-historical context of the NLS-MW. The NLS-MW participants are all members of the "Silent Generation" (Dimock 2019), Americans who were born between the mid-1920s to the mid1940s and entered adolescence and early adulthood during a period of low divorce rates but profound gender- and race-based stratification. Finally, we conceptually disaggregate economic resources into distinct components of income and wealth and then consider why different components may differentially account for the association between divorce and mortality among older White and Black women.

\section{BACKGROUND}

Prior research consistently finds that married adults have a lower risk of all-cause mortality compared to all other marital statuses (Dupre, Beck et al. 2009, Liu 2009, Rendall, Weden et al. 2011). The "marital resource model" explanation of this recurring finding emphasizes the material advantages provided by couples' pooling of economic resources (Lillard and Waite 1995, Liu 2009, Liu, Umberson et al. 2020). Through sharing a household and participating in economies of scale, married couples generally have fewer expenditures than a single adult while also having the resources of two adults (Waite 1995). Even unemployed spouses contribute to their family' economic stability through supportive actions such 
as childcare and food preparation (Becker 1973). As a result, married women - especially married, White women-report significantly higher household incomes and wealth than unmarried women (Smock, Manning et al. 1999, Hirschl, Altobelli et al. 2003), and these economic resources have robust associations with mortality in older populations (Duncan, Daly et al. 2002, Demakakos, Biddulph et al. 2016).

Economic resources are related to mortality risk because they capture socioeconomic status (SES) and stressful "wealth shocks" in adulthood. Health disparities research generally views SES as one's levels of educational, occupational, and economic attainments (Wolfe 2015). Those who attain more schooling generally obtain more prestigious jobs with higher earnings, and through an accumulation of "knowledge, money, power, prestige, and social connections" (Link and Phelan 1995: pg. 88), SES helps high-attaining individuals avoid and treat disease. Although education and occupation are key components of SES, they tend to stabilize in adulthood while one's economic resources continue to vary, reflecting the continued accumulation of advantages and disadvantages that occurs in adulthood. Economic resources also reflect wealth shocks (large drops in wealth) that activate physiological stress responses and increase mortality risk (Boen and Yang 2016, Pool, Burgard et al. 2018). For example, Pool, Burgard et al. (2018) found that experiencing a loss of 75\% or more in net worth over a 2-year period significantly increased the risk of all-cause mortality in a U.S. sample of older adults.

Divorce is a common cause of large losses in economic resources due to, e.g., splitting assets, losing spousal earnings, purchasing new housing, moving costs, and legal expenses (Smock 1993, Zagorsky 2005, McLanahan and Percheski 2008, Addo and Lichter 2013), and the economic fallout from divorce may result in chronic strains that ultimately reduce longevity (Amato 2010). A few notable studies build on this idea and provide empirical evidence that economic resources play a significant role in the relationships between marriage, marital disruptions, and mortality risk.
Lillard and Waite (1995) examined marriage and mortality with a large longitudinal sample of adult men and women in the U.S. and found that controlling for household income accounted for most of the protective effect of marriage for women but not men. Likewise, Dupre et al. (2009) found that education, occupation, and net worth substantially reduced the association between divorce and mortality risk among women. More recently, Hui, Umberson, and Xu (2020) examined data on widowhood after 50 and found that both income and wealth help explain the widowhood effect on mortality, especially among White women. Taken together, these studies provide evidence that economic resources are key to understanding the association between divorce and mortality risk, but this area of research has not yet identified which specific economic resources are most important.

\section{The High Price of Divorce for Silent Generation Women}

Economic resources provide a healthier and longer life, but socio-historical forces determine who gets the opportunity to attain an education and to what degree the labor market financially rewards their academic achievements (Meier, Stewart et al. 1989). The U.S. stratification system has historically privileged White men over women and racial-ethnic minorities, especially when Silent Generation women were coming of age in the earlier half of the twentieth century. Opportunities to attain high-earning positions and accumulate personal wealth were extremely limited for women, making the social and economic costs of divorce for women especially high (see Holden and Smock 1991). Given the vulnerable social position of Silent Generation women, divorce could easily mean financial ruin at a key period of the life course for asset accumulation, which may have an especially detrimental effect on the mortality risk of women who are now entering later life.

Hypothesis 1: Midlife economic resources significantly reduce the association between divorce and mortality risk among Silent Generation women. 
To provide a comprehensive test of Hypothesis 1, we conceptually disaggregate income and wealth into their most basic parts. We consider personal earnings, household income, net worth, housing wealth, vehicle wealth, financial wealth, and indebtedness. A growing body of research provides evidence that these economic resources, as well as gains and losses in these resources, can have independent relationships with health (Boen and Yang 2016, Wolfe, Baker et al. 2019, Boen, Keister et al. 2020). Below, we discuss in greater detail how different economic resources may explain the association between divorce and survival among older women.

\section{Household Income and Women's Earnings}

Most studies of divorce and economic resources focus on the total income of household members, but the gap between household income and Silent Generation women's personal earnings may offer important insights into the economic resources underlying marital inequalities in mortality risk. With respect to income, one prior study of the Silent Generation found that over twenty-five percent of divorced women entered poverty during the first five years after their marriage ended (Morgan 1989). Because greater household income can be used to purchase goods or services that promote health (e.g., access to private medical care, healthier diets, and gym memberships), it is considered a key social determinant of mortality among older populations (Duncan, Daly et al. 2002). Thus, the reduction in household income experienced by women after divorce is a potential reason for their higher mortality risk (Lillard and Waite 1995).

Divorce has a more complicated relationship with women's earnings. In some circumstances, divorce increases women's earnings because many women must enter (or re-enter) the labor force or increase their work hours to replace their spouses' earnings (Tach and Eads 2015). We know less about how personal earnings are tied to mortality compared to household income because studies rarely include both measures within the same analysis. To the extent that personal earnings may replace lost household income, we would expect personal earnings to hold more significance than household income for divorced women, representing the extent to which a woman is able to engage in the labor force for her own financial well-being. Given these differences between household income and women's earnings, we expect that women's earnings are uniquely relevant to survival among older women when compared to their household income.

Hypothesis 2: Women's personal earnings reduce the association between divorce and survival among Silent Generation women more than household income.

\section{Wealth and its Components}

As a cumulative measure of economic well-being, wealth offers a distinct - arguably optimalindicator of social inequality, reflecting important resources for health not captured by income (Keister 2014, Hällsten and Pfeffer 2017). Wealth differs from earnings-based measures of economic resources in that it has a higher degree of stability both within one's life and across family generations. Wealth enables a healthier lifestyle and provides a financial safety net during economic shocks that might otherwise negatively impact psychological well-being and physical health (Boen and Yang 2016, Pool, Burgard et al. 2018).

Hypothesis 3: Wealth reduces the association between divorce and survival among Silent Generation women more than household income and individual earnings.

Sociological research on wealth and its correlates generally focuses on net worth. Net worth is a summation of one's assets (typically including housing wealth, financial wealth, and vehicle wealth) minus their total debts. However, there are several reasons to expect that these components of net worth may play distinct roles in explaining the divorce-mortality association.

First, divorce substantially reduces housing wealth among older women (Addo and Lichter 
2013), a key mechanism of wealth accumulation in adulthood with implications for health and wellbeing (Yilmazer, Babiarz et al. 2015). Because housing wealth is often the largest source of wealth among older adults (Killewald and Bryan 2016), it often drives differences in net worth among this group. Homes typically appreciate with time, providing financial stability in later life. Using data from the National Longitudinal Surveys of Youth 1979 (NLSY-79), Killewald and Bryan (2016) found that each additional year of homeownership increased midlife wealth by about $\$ 6,800$. Housing wealth also has use value, meaning that it carries a practical and instrumental purpose-namely providing a place for shelter. Houses with more initial worth tend to be made from building materials free of known carcinogens, located in safer neighborhoods with less crime, and-in terms of economic wellbeing-provide better returns when sold (Woldoff and Ovadia 2009). However, losing home wealth is especially stressful and increased home foreclosures between 2005 and 2010 may even be partially responsible for upticks in suicides among middle-aged adults (Houle and Light 2014).

Second, the causes and utility of financial wealth - which includes cash, savings, stocks, bonds and other related resources (Keister 2014, Hällsten and Pfeffer 2017) - have a few notable qualities that are potentially related to divorce and survival. Savings and investments can provide financial support during divorce as the separation of households increases the individual costs of living, although this also means divorce can deplete these economic resources. Financial wealth may also reflect unobserved cognitive (e.g., successful implementation of money management strategies) and non-cognitive (e.g., forethought and delayed gratification) abilities related to health and health behaviors (Mirowsky and Ross 2015). When considered together, these characteristics of financial wealth suggest that women's savings and investments (i.e., financial wealth) may help explain the association between divorce and mortality risk.
Third, fewer studies have considered whether vehicle wealth is related to mortality, but there are reasons to expect it would be, albeit to a lesser extent than home or financial wealth. Cars are a high-priced asset that may provide information on individual's economic circumstances and general lifestyle that other indicators of income and wealth do not completely capture. For example, vehicle wealth provides a useful measure of disposable income, which can vary substantially depending on factors such as the living expenses of respondents' geographic residence. Similar to homes, vehicles also have a use-value. Vehicle wealth is consequential as an indicator of personal transportation availability and reliability, which is important for employment and overall well-being. Cars, however, are a quickly depreciating asset with few long-term financial benefits or health advantages. Past studies indicate that almost all of the median wealth of single Black women can be attributed to their vehicles, reflecting their lower relative levels of wealth more broadly (Addo and Lichter 2013). We discuss this in more detail in the following section on racial inequalities.

Fourth, people who divorce are significantly more likely to enter indebtedness and declare bankruptcy than their married counterparts (Zagorsky 2005). The ability to acquire some amount of debt can be a sign of financial privilege, especially in early adulthood, but high indebtedness in middle adulthood is an indicator of serious financial problems. Although married persons also experience financial difficulties and acquire debt, they generally accumulate less debt and pay it off faster than similar others who have divorced (Caputo 2008). With respect to health, indebtedness is an inherently stressful experience that also constrains one's ability to purchase health-enhancing goods and services (Dwyer 2018), and indebtedness and its economic repercussions can increase anxiety and mental health problems (Drentea and Reynolds 2012).

Hypothesis 4: The components of wealthincluding housing wealth, financial wealth, vehicle wealth, and indebtedness- 
differentially account for the relationship between divorce and survival.

\section{Racism and Racial Differences in the Economic Benefits of Marriage}

Prior studies find that the association between divorce and health among Black populations is small or nonexistent (Liu and Reczek 2012, Roxburgh 2014, Dupre 2016). The lack of an association between divorce and health may reflect the lack of an economic benefit from marriage, especially for Silent Generation Black women who came of age prior to the Civil Rights movement. As a result of institutionalized racial inequalities of opportunity in the educational system and labor market at this point in U.S. history, Black men were unable to provide their families with the same financial security as White men (TomaskovicDevey, Thomas et al. 2005). Silent Generation Black families also faced profound discrimination from consequential organizations outside of the labor market, e.g., real estate companies and banks that blocked housing in wealthier, White neighborhoods (Hwang, Hankinson et al. 2014). Predatory lending practices by banks that targeted minority populations also meant that even homeownership among Black families provided a smaller economic gain that what White families received from purchasing a house (Hwang, Hankinson et al. 2014, Killewald and Bryan 2016, Dwyer 2018). Thus, divorce was less consequential for the economic well-being and survival of Black women in this generation due to institutional and organizational practices that constrained the ability of Black families to accumulate economic resources.

Because marriage as a path towards economic standing was less the case for Black women in the Silent Generation (Zagorsky 2005, Oliver and Shapiro 2006), they were much more likely to work outside of the home than White women, typically in domestic jobs for low wages (e.g., nanny, housekeeper), which meant that Black women often made a larger financial contribution to their households than married White women (Fry and Cohn 2010 ). Most of the net worth of single, Black women can be attributed to the value of motor vehicles instead of their housing, which is the primary source of wealth for White women (Addo and Lichter 2013). Thus, personal earnings, vehicle wealth, and financial wealth may be important for identifying the full extent of economic resources among Silent Generation Black women.

Hypothesis 5: Racial inequalities in survival extend from the economic benefits of marriage for Silent Generation White women.

\section{METHOD}

\section{Data}

We used data from the NLS-MW cohort (https://www.nlsinfo.org). The NLS-MW began in 1967 with a nationally representative sample of 5,083 noninstitutionalized women between the ages of 30 and 44, meaning they were born between 1923 and 1937 . We chose these data because of several unique strengths. First, the NLS-MW had 20 follow-up interviews between 1968 and 2003, providing over three decades of detailed information on women's economic wellbeing and marital transitions. Although attrition is inevitable in longitudinal surveys, even in the final 2003 survey, 36 years after the sample selection, the NLS was still able to collect interviews from 62 percent of living respondents. Second, a key feature of the NLS cohorts was an oversample of Black Americans, which allows more detailed racial comparisons. Finally, the NLS-MW includes updated mortality data for respondents who were deceased by 2012 that was collected through the Demographic Survey Division of the U.S. Census Bureau and the National Center on Health Statistics.

To utilize all cases, we addressed missing data using multiple imputation to construct 35 complete data sets, which is the number recommended given the proportion of missing information in the analysis sample (Graham, Olchowski et al. 2007). Vehicle wealth had an especially high rate of missing because the NLS-MW did not ask about the value of vehicles in the 1967, 1982, 1987, or 1995 surveys. However, results based on listwise 
deletion led to the same overall conclusions with respect to the relationships between divorce, economic resources, and survival (see Appendix).

\section{Measures}

Age of Death. The NLS-MW includes the year of death for deceased women. This information was obtained by linking respondents to their death certificates with the National Death Index and Social Security Death Index through 2012. We used this information to create an indicator of age of death for all women who were deceased by 2012. To address age differences in the 1967 survey, we dropped women who died prior to the age of $45(\mathrm{~N}=58)$ and set the age of entry into the risk set to 44. By 2012, 44 percent of the total sample were deceased.

Divorce Status. The NLS-MW contains detailed information on women's marital status and transitions throughout the survey period, in addition to information on marital transitions prior to the beginning of the survey in 1966. Our primary variable of interest is a binary indicator of women who divorced by the age of $44(\mathrm{~N}=654)$. We also include controls for women who never married ( $\mathrm{N}$ $=216)$, women who remarried $(\mathrm{N}=367)$, and women who were widowed before the age of $65(\mathrm{~N}$ $=851)$. Because of our interest in the association between divorce and midlife economic resources, we exclude women who divorced after the age of $44(\mathrm{~N}=239)$. In supplemental analyses, we ran models without dropping women who divorced after 44, which yielded the same pattern of statistical significance and substantive conclusions we discuss here (see Appendix). We also dropped 13 additional cases in which the type of marital dissolution women experienced could not be identified.

Economic Resources. Our operationalizations of economic resources incorporate contemporary scholarship on wealth while also adjusting for the NLS-MW women's age range and the NLS-MW data collection process. Based on the recommendations of Killewald, Pfeffer et al. (2017), we used the average of the res6endent's economic resources using financial information collected when women were between the ages of 45 to 64 , i.e., middle adulthood, in order to reduce attenuation bias. We use this age range because (1) it represents a critical period of wealth accumulation in midlife before people begin leaving the labor force (Hilton and Anderson 2009), (2) the majority of women in the sample divorced prior to 45 (72 percent of divorces), and (3) it accounts for age differences due to respondents being 30 to 44 years old when the NLS-MW began in 1967. Finally, following the work of Hällsten and Pfeffer (2017), we constructed variables denoting respondent's relative rank (i.e., their value in the empirical cumulative distribution function bounded by 0 and 1) with respect to their average household income, personal earnings, net worth, housing wealth, financial wealth, and vehicle wealth.

Household Income and Women's Earnings. In every survey year, the NLS-MW asked respondents several questions about the income they receive from their wages, businesses, and other household members. Using this information, we created variables for women's personal earnings using NLS questions that asked, "How much did you receive from wages, salary, commissions, or tips from all jobs, before deductions for taxes or anything else?" To create household earnings, we added respondent's earnings to the total earnings of their spouse, if married, and other family members living in the household.

Net Worth and its Components. Using information from twelve survey waves spanning over thirty years, 1967 to 2003, we constructed two sets of wealth measures, net worth and the components of wealth potentially related to divorce and health. Beginning in the first survey, the NLSMW collected detailed information about women's assets, including the value of their houses, vehicles, savings, investments, business assets, mortgages, loans, and other debts. If the respondent was married, this information included the assets of respondent and their spouse. For example, the NLS-MW asked, "Do you (or your husband) have any stocks, bonds, or mutual funds?" In later 
surveys, the NLS-MW slightly changed the wording of asset-related to "(or your husband/partner)." Net worth variables were created by the NLS-MW by adding up all assets and subtracting total debt.

To measure the components of net worth, we used questions about women's assets to operationalize (1) housing wealth, measured as the market value of the primary, owner-occupied home or apartment the respondent owns; (2) financial wealth, measured as the total value of checking, savings, and investments (e.g., stocks, bonds, mutual funds); (3) vehicle wealth, measured as the market value of the primary vehicle the respondent owns; and (4) indebtedness, measured as a binary indicator of negative net worth. We chose to use a binary indicator of indebtedness instead of women's relative rank of debt because many wealthy women had higher levels of debt due to loans for more expensive homes and vehicles, meaning that a higher rank debt could be an indicator of economic well-being. Negative net worth, which we refer to as simply indebtedness, is more indicative of stress-inducing financial situations (e.g., foreclosure and bankruptcy) that may be related to women's longevity.

Controls. The analysis also adjusted for several key sociodemographic variables related to women's education, midlife employment, household size, health, and early-life social conditions. Educational attainment was operationalized as years of schooling. Employment is a binary variable identifying women who reported any midlife employment. This control is important as employment status is a key factor in understanding women's earnings. To adjust for the presence of children, partners, and other household members that may affect women's economic status, we also control for the average number of people living with women when they were in middle adulthood. To control for women's prior health problems, which reduce women's wealth accumulation (Wilkinson, Ferraro et al. 2019), we created a categorical measure of women's selfreported health status in 1967. Women were asked to rate their health relative to other women their age. Respondents could answer excellent, good, fair, or poor. We combined the fair and poor categories due to the small number of women who reported poor health.

The analysis also adjusted for Adolescent SES and family structure, which are negatively associated with quality of romantic relationships, adult wealth, and mortality risk (Montez and Hayward 2014, Umberson, Williams et al. 2014, Bernardi, Boertien et al. 2019). We operationalized adolescent family structure as living with both biological parents, living with mother but not biological father, or living in some other family structure at age 15. Because the occupation of Silent Generation women's fathers was the principal determinant of family SES prior to the expansion of education in the U.S., we measured adolescent SES as a categorical variable indicating their parents' occupation (Wolfe, Bauldry et al. 2018, Wolfe, Bauldry et al. 2018). The categories include manual (private household, service, operators, transportation, or laborers), farming (farmers and farm managers), skilled (technical and related support, sales, administrative support, protective services, or the military), and whitecollar (managerial or professional occupations). We used fathers' occupation information or, if fathers' information is missing, we used information about women's mothers $(\mathrm{N}=50)$.

\section{Analysis}

The analysis proceeded in two steps. First, we examined the associations between marital status and components of income and wealth. Because all of our measures of economic resources (excluding indebtedness) were measured as respondents' rank in the cumulative distribution function, we use fractional logistic regression models, which are appropriate when the dependent variable has values ranging from 0 to 1 (StataCorp 2019). The models fit by Stata's command fracreg are quasilikelihood estimators like generalized linear models. For a more detailed discussion of quasilikelihood estimation and other applications of fractional regression models see Papke and Wooldridge (1996) and Wooldridge Wooldridge 
(2010). We used logistic regression when the model outcome was indebtedness.

In the second step of the analysis, we examined women's mortality risk and the degree to which household income, women's earnings, net worth, housing wealth, vehicle wealth, financial wealth, and indebtedness attenuate marital inequalities in mortality risk. We used Gompertz proportional hazards models with age of entry set to 44. Age of death, or age in 2012 for those still living, was measured in years. Gompertz models allow for an increasing hazard rate over time and are thus common when modeling survival (Preston, Heuveline et al. 2001). To test whether the size of coefficients were significantly reduced after controlling for economic resources, we used the suest command in Stata 16. Additionally, to provide a visualization of marital and racial inequalities in survival and the degree to which these inequalities are influenced by different components of economic resources, we also display the predicted median age of death across several different Gompertz proportional hazards models with interactions between race and marital status.

\section{Endogeneity}

A common problem for observational studies involves endogeneity, i.e., selection effects. This means that statistically significant relationships we observe could potentially reflect unobserved background factors that cause divorce, lower socioeconomic attainment, and higher mortality risk. We addressed this by controlling for rank average economic resources prior to midlife (30 to 44 years old) and several background characteristics, including women's education, parents' occupation, and women's family structure in adolescence. Nevertheless, we interpret results cautiously as a descriptive, but still important, first look into the midlife economic pathways that connect marital status to mortality.

\section{RESULTS}

Table 1 contains a full list of analysis variables with descriptive statistics $(\mathrm{N}=4,668)$. All economic indicators are displayed in 2017 constant dollars and in units of $\$ 10,000$. By 2012, a larger percentage of Black women was deceased-51 percent compared to 41 percent of White women. After splitting the sample by women who were continuously married and women who experienced a divorce (not shown), we also found that divorced White women experienced a similar percentage of deaths, 47 percent, as married and divorced Black women, 53 and 47 percent, respectively. only 39 percent of married White women were deceased. Other indicators of economic resources and family structure had a similar pattern: White married women were notably more advantaged than Black women and divorced White women.

-- Table 1 here --

\section{Divorce and Midlife Economic Resources}

We first consider the association between divorce and midlife economic resources in order to provide the foundation for examining our research questions. To visualize how marital and racial inequalities changed across model and to gain a better sense of the relative sizes of associations we found, Figure 1 displays the predicted differences between married and divorced women in their rank economic resources (see Appendix for model coefficients). Figure 1 highlights a few notable characteristics of the relationship between divorce and economic resources. First, White women who divorced had significantly higher earnings than their married counterparts but lower rank family income. This suggests that divorced White women increased their personal earnings in middle adulthood to maintain the same overall income they had when married. For Black women, we found no evidence of differences in rank personal earnings or family income by divorce status $(p>$ $.05)$.

Second, we found that both Black and White women who divorced had significantly lower vehicle wealth and significantly higher probabilities of midlife indebtedness. Third, we found significant differences in midlife housing wealth between married and divorced White women but not between married and divorced 
Black women. We also found evidence that divorce is associated with lower rank savings and investments for White women $(p<.05)$, but these differences were relatively small compared to differences in housing and vehicle wealth.

-- Figure 1 here --

\section{Divorce, Economic Resources, and Mortality Risk}

We now turn to our research questions: (1) What specific economic resources reduce the association between divorce and mortality risk among older women? and (2) Do these resources differ for White and Black women? Table 2 contains hazard ratios from Gompertz proportional hazards models stratified by race. In Model 1, we began with a base model that did not include economic resources or sociodemographic controls. divorced White women have a mortality risk $1.52(p<.001)$ times higher than the risk for continuously married White women, whereas the survival of Black women was unrelated to their marital status. the difference between Black and White women in the size of the association between divorce and survival was significant. Model 2 contains household income and women's earnings. In supplemental analyses (not shown), we found that household income and women's earnings both reduced the association between divorce and mortality a similarly small amount, which was not significant $(p>.05)$. Marital inequalities in mortality were most attenuated in Model 3, which adjusted for women's net worth. Model 3 is also the only model for White women in which none of the marital statuses were significantly different than the married reference group.

-- Table 2 here -

Table 3 includes results from additional Gompertz proportional hazards models that considered the components of net worth separately. For White women, both housing and vehicle wealth were statistically significant $(p<.01$ and $p$ $<.05$, respectively). the largest reduction in the size of the association between divorce and survival occurred when we controlled for housing wealth. The hazard ratio for divorce dropped from $1.52(p$ $<.001)$ in Model 1 of Table 2 to $1.22(p<.05)$ in Models 1 and 5 of Table 3. For Black women, vehicle wealth and savings/investments were the only components of wealth significantly associated with mortality risk $(p<.05$ and $p<.01$, respectively). For Model 5, we combined all of the components of wealth that were statistically significant in Models 1-4. For White women this included housing and vehicle wealth, and for Black women this included vehicle and financial wealth. This final model confirmed the importance of housing wealth for White women's mortality risk and savings/investments for Black women's mortality risk.

\section{-- Table 3 here --}

To test whether the differences in the coefficients for divorce across Gompertz proportional hazards models were statistically significant, we used the suest command in Stata 16 (see Appendix). We observed significant reductions in the coefficient for divorce after including net worth (Model 1 compared to Model 3 of Table 2) and wealth components (Model 1 of Table 2 compared to Model 5 of Table 3). However, we did not find significant differences between Models 1 and Model 2 of Table 2, meaning that adding household income and women's earnings to models of survival did not significantly attenuate the divorce-mortality association.

Figure 2 displays the predicted median age of death across Gompertz proportional hazards models with interactions between race and marital status (see Appendix). In Models 2 through 7, each measure of wealth reduced marital and racial differences in the predicted median age of death. Marital and racial inequalities in mortality were smallest in models that included net worth or housing wealth. Thus, wealth-housing wealth in particularly - appears to be the critical economic resource for reducing not only the association 
between divorce and survival for White women but also racial inequalities in mortality risk.

-- Figure 2 here --

\section{DISCUSSION}

Drawing from diverse lines of scholarship, we argued that the U.S. stratification system made marrying a White man a tacit requirement for accumulating economic resources when Silent Generation women were entering adulthood. Reflecting these gender- and race-based inequalities, in our analysis of the NLS-MW of women, born between 1923 and 1937, we found that divorce and midlife wealth, especially housing wealth, were strongly associated with one another and with the longevity of White women. For Black women, however, we did not observe any evidence of a relationship between divorce and survival, though we did find that midlife net worth, earnings, and financial wealth were associated with lower mortality hazard. Our findings provide further evidence that race and family structure are central to social stratification and health disparities in the U.S. (Hirschl, Altobelli et al. 2003, Addo and Lichter 2013, Tach and Eads 2015). We discuss our key findings and their implications and limitations in more detail below.

First, we found that wealth and its components significantly reduced the association between divorce and survival among Silent Generation White women. Although divorce was also related to midlife household income and women's earnings, these did not affect the divorce-survival association. These results support a growing consensus in social science research that wealth is critical to identifying SES and, in turn, the full extent of health disparities in a population (Duncan, Daly et al. 2002, Pollack, Chideya et al. 2007). Income offers a snapshot of one's economic well-being, but it does not seem to capture the accumulation of financial decisions, unobserved human capital, life events, and familial advantages to the same degree that wealth does (Killewald, Pfeffer et al. 2017). Our results reflect this conceptual distinction; wealth seemed to act as a conduit of the socioeconomic disadvantages flowing from divorce.

Second, after splitting wealth into its components, we found that housing wealth most attenuated marital and racial inequalities in mortality risk. Why is housing wealth so important for understanding mortality disparities among Silent Generation women? as an appreciating asset, housing wealth is able to gain value over time, but it also has present-day use value, which is unique even among appreciating assets (Killewald and Bryan 2016). Unlike other economic resources, housing wealth reflects both property ownership and neighborhood characteristic such as crime, walkability, and medical resources (Woldoff and Ovadia 2009, Yilmazer, Babiarz et al. 2015), all of which are associated with mortality risk (Lochner, Kawachi et al. 2003). The loss of this, especially if unexpected, represents a profound disadvantage with implications for life expectancy. given the unique contributions of housing value towards understanding longevity and marital- and racialbased disparities, these results highlight the important of measuring housing wealth and not just homeownership or non-housing wealth. Thus, our results provide further evidence that housing wealth is an important identifier of midlife economic and health-related advantages.

A third notable contribution of this study is our comparisons of Black and White women. Overall, divorce had few economic consequences for Black women. the exception being that married Black women generally had greater vehicle wealth and less debt than divorced Black women. Neither vehicle wealth nor indebtedness, however, had a robust association with Black women's mortality risk. This result supports past studies that found marital status matters less for the wealth and health of Black adults (Roxburgh 2014, Dupre 2016). Within the Silent Generation, the privileges afforded to the married, including health and longevity, seem to be reserved for White women, reflecting their proximity to the White men who had unconstrained access to the labor market and few obstacles to wealth accumulation. Due to the 
broader context of institutionalized racism in the U.S. that is evident across multiple institutions including financial (e.g., banks, housing markets), health care, and educational, Black women had less to gain from marriage and thus less to lose from divorce. Black women's longevity had a more robust relationship with financial wealth, which may reflect the relative independence that savings have from spousal attainment and racialized lending processes (Hwang, Hankinson et al. 2014, Killewald and Bryan 2016, Dwyer 2018). Nevertheless, we should not disregard marriage for Black women, as race and family structure are inherently intertwined in the U.S. Furthermore, we found that divorced Black women have a notable economic disadvantage with respect to indebtedness and vehicle wealth, which is consequential as personal transportation availability and reliability is important for employment and overall well-being. In sum, our results suggest that divorce was not a primary source of inequality among Silent Generation Black women to the same degree that it was among Silent Generation White women.

\section{Limitations and Opportunities for Future Research}

Our study is unique in its ability to examine the connections between marital and racial inequalities in economic resources and older women's longevity, but our findings should be interpreted in light of their limitations. First, even though we adjust for a number of potential confounders, including women's average economic resources prior to midlife, we suspect that at least some portion of the associations we find are caused by unobserved characteristics in women and their social contexts. Related, although our interest in women's survival and midlife economic resources made the NLS-MW the ideal dataset, the NLS-MW began when women were between the ages of 30 to 44 , and data collection skipped several years. This means that we are unable to measure the exact timing of all marital dissolutions and economic losses. Despite threats to causality, our results still provide important new information about the economic factors underlying marital and racial inequalities in women's survival. Future research, however, should examine earlier periods of the life course in order to shed light on the characteristics of women's lives that make marriage and wealth accumulation difficult, and whether those characteristics are responsible for the associations we see between marital status, economic resources, and mortality risk.

Second, although we controlled for household size and considered women's number of children in supplemental analyses, future research should examine family formation more extensively. Recent studies have found that wealth and mortality risk are complex processes that involve multiple familial generations and vary by race (Hällsten and Pfeffer 2017, Reyes, Hardy et al. 2018, Wolfe, Bauldry et al. 2018). Divorce is likely a moderating factor in these processes, but we currently know little about how divorce affects the multigenerational accumulation of wealth and its health advantages.

Third, as an analysis of a secondary dataset, we did not have access to detailed measures of racism and discrimination that may also play important roles. A range of factors related to institutionalized racism likely impact marriage markets, labor markets, and health care markets. Future research should employ multiple methods, especially using a comparative historical framework, and directly examine how various institutional processes interact to constrain the economic attainment of Black families.

Finally, we did not consider the emotional and behavioral problems that are often related to divorce. This issue is related to our first limitation in that mental health and substance abuse are an important set of currently unobserved characteristics that future work should consider in more detail. Future research should consider whether behavioral problems, depression, and substance abuse early in life create recurring relationship problems, damage health, and eventually increase mortality risk. Future research should also consider whether the distress and isolation that follow marital strain and divorce act 
as more proximate determinants of poor health in later adulthood. In other words, are marital inequalities the catalyst of health disparities or the final results of lifelong cumulative disadvantage processes?

\section{Conclusion}

By examining the components of economic resources, we were able to add further evidence and detail to the assertion that Silent Generation Black women's economic well-being was less tied to marriage and divorce than White women's economic well-being. This suggests, as numerous scholars have argued (Oliver and Shapiro 2006, Roxburgh 2014, Darity, Hamilton et al. 2018), that the racial wealth gap is not due to lower rates of marriage or higher rates of divorce within Black communities but rather the systematic practices that constrained Black men and women's abilities to accumulate economic resources for the benefits of their families and their own mortality. Policies to reduce the racial wealth gap must look beyond family dynamics and marital experiences and instead address the root structural causes of health disparities: institutionalized racism and sexism. Suggested policies include targeted reparation programs and direct federal job creation programs (Maye 2019), all solutions that would benefit Black adults across genders and marital statuses. Beyond reducing the racial wealth gap, our study provides evidence that these policies might also reduce racial disparities in mortality by developing programs targeted at improving homeownership and home value for Black women. for example, creating equitable homeownership policies and improving the quality of schools in poor neighborhoods could help reduce the profound financial and mortality gaps we see between marital and racial groups in the U.S. 


\section{REFERENCES}

Addo, F. R. and D. T. Lichter (2013). "Marriage, Marital History, and Black-White Wealth Differentials Among Older Women." Journal of Marriage and Family 75(2): 342-362.

Amato, P. R. (2010). "Research on Divorce: Continuing Trends and New Developments." Journal of Marriage and Family 72(3): 650-666.

Becker, G. S. (1973). "A theory of marriage: Part I." Journal of Political economy 81(4): 813846.

Bernardi, F., D. Boertien and K. Geven (2019). "Childhood Family Structure and the Accumulation of Wealth Across the Life Course." Journal of Marriage and Family 81(1): 230-247.

Boen, C., L. Keister and B. Aronson (2020). "Beyond Net Worth: Racial Differences in Wealth Portfolios and Black-White Health Inequality across the Life Course." Journal of Health and Social Behavior doi:10.1177/0022146520924811.

Boen, C. and Y. C. Yang (2016). "The physiological impacts of wealth shocks in late life: Evidence from the Great Recession." Social Science \& Medicine 150: 221-230.

Bourassa, K. J., J. M. Ruiz and D. A. Sbarra (2019). "Smoking and Physical Activity Explain the Increased Mortality Risk Following Marital Separation and Divorce: Evidence From the English Longitudinal Study of Ageing." Annals of Behavioral Medicine 53(3): 255-266.

Caputo, R. K. (2008). "Marital Status and Other Correlates of Personal Bankruptcy, 1986-2004." Marriage \& Family Review 44(1): 5-32.

Darity, W., D. Hamilton, M. Paul, A. Aja, A. Price, A. Moore and C. Chiopris ( 2018). What We Get Wrong About Closing the Racial Wealth Gap. Insight Center for Community Economic Development Samuel DuBois Cook Center on Social Equity. Retrieved from https://socialequity.duke.edu/sites/socialequity.duke.edu/files/siteimages/FINAL\%20COMPLETE\%20REPORT_.pdf.

Demakakos, P., J. P. Biddulph, M. Bobak and M. G. Marmot (2016). "Wealth and mortality at older ages: a prospective cohort study." J Epidemiol Community Health 70(4): 346-353.

Dimock, M. (2019). Defining generations: Where Millennials end and Generation Z begins. Washington, D.C., Pew Research Center. Retreived from https://www.pewresearch.org/facttank/2019/01/17/where-millennials-end-and-generation-z-begins.

Drentea, P. and J. R. Reynolds (2012). "Neither a Borrower Nor a Lender Be The Relative Importance of Debt and SES for Mental Health Among Older Adults." Journal of Aging and Health 24(4): 673-695.

Duncan, G. J., M. C. Daly, P. McDonough and D. R. Williams (2002). "Optimal Indicators of Socioeconomic Status for Health Research." American Journal of Public Health 92(7): 1151 1157.

Dupre, M. E. (2016). "Race, marital history, and risks for stroke in US older adults." Social Forces 95(1): 439-468.

Dupre, M. E., A. N. Beck and S. O. Meadows (2009). "Marital Trajectories and Mortality Among US Adults." American Journal of Epidemiology 170(5): 546-555.

Dwyer, R. E. (2018). "Credit, Debt, and Inequality." Annual Review of Sociology 44: 237-261.

Elder, G. H. and L. K. George (2016). Age, Cohorts, and the Life Course. Handbook of the Life Course: Volume II. J. M. Shanahan, T. J. Mortimer and M. Kirkpatrick Johnson. Cham, Springer International Publishing: 59-85. 
Fry, R. and D. V. Cohn (2010). Women, men, and the new economics of marriage. . Washington, DC. , Pew Research Center. Retrieved from: https://www.pewsocialtrends.org/2010/01/19/women-men-and-the-new-economics-ofmarriage.

Graham, J. W., A. E. Olchowski and T. D. Gilreath (2007). "How many imputations are really needed? Some practical clarifications of multiple imputation theory." Prevention Science 8(3): 206-213.

Hällsten, M. and F. T. Pfeffer (2017). "Family Wealth and Grandchildren's Educational Achievement in Sweden." American Sociological Review 82(2): pp. 328-360.

Hilton, J. M. and T. L. Anderson (2009). "Characteristics of Women With Children Who Divorce in Midlife Compared to Those Who Remain Married." Journal of Divorce \& Remarriage 50(5): 309-329.

Hirschl, T. A., J. Altobelli and M. R. Rank (2003). "Does Marriage Increase the Odds of Affluence? Exploring the Life Course Probabilities." Journal of Marriage and Family 65(4): 927-938.

Holden, K. C. and P. J. Smock (1991). "The Economic Costs of Marital Dissolution: Why Do Women Bear a Disproportionate Cost?" Annual Review of Sociology 17: 51-78.

Houle, J. N. and M. T. Light (2014). "The Home Foreclosure Crisis and Rising Suicide Rate, 2005 to 2010." American Journal of Public Health 104(6): 1073-1079.

Hwang, J., M. Hankinson and K. S. Brown (2014). "Racial and Spatial Targeting: Segregation and Subprime Lending within and across Metropolitan Areas." Social Forces 93(3): 10811108.

Keister, L. A. (2004). "Race, Family Structure, and Wealth: The Effect of Childhood Family on Adult Asset Ownership." Sociological Perspectives 47(2): 161-187.

Keister, L. A. (2014). "The One Percent." Annual Review of Sociology 40(1): 347-367.

Killewald, A. and B. Bryan (2016). "Does Your Home Make You Wealthy?" RSF: The Russell Sage Foundation Journal of the Social Sciences 2(6): 110-128.

Killewald, A., F. T. Pfeffer and J. N. Schachner (2017). "Wealth Inequality and Accumulation." Annual Review of Sociology 43: 379-404.

Lillard, L. A. and L. J. Waite (1995). "'Til Death Do Us Part: Marital Disruption and Mortality." American Journal of Sociology 100(5): 1131-1156.

Link, B. G. and J. Phelan (1995). "Social Conditions as Fundamental Causes of Disease." Journal of Health and Social Behavior 35(Extra Issue): 80-94.

Liu, H. (2009). "Till Death Do Us Part: Marital Status and U.S. Mortality Trends, 1986 - 2000." Journal of Marriage and Family 71: 1158-1173.

Liu, H. and C. Reczek (2012). "Cohabitation and US adult mortality: An examination by gender and race." Journal of Marriage and Family 74(4): 794-811.

Liu, H., D. Umberson and M. Xu (2020). "Widowhood and Mortality: Gender, Race/Ethnicity, and the Role of Economic Resources." Annals of Epidemiology.

Lochner, K. A., I. Kawachi, R. T. Brennan and S. L. Buka (2003). "Social capital and neighborhood mortality rates in Chicago." Social science \& medicine 56(8): 1797-1805.

Malgaroli, M., I. R. Galatzer-Levy and G. A. Bonanno (2017). "Heterogeneity in Trajectories of Depression in Response to Divorce Is Associated With Differential Risk for Mortality." Clinical Psychological Science 5(5): 843-850. 
Maye, A. (2019). Progressive Solutions to Reducing the Racial Wealth Gap. Washington, DC. , Center for Economic and Policy Research (CEPR). Retrieved from https://www.cepr.net/progressive-solutions-to-reducing-the-racial-wealth-gap/.

McLanahan, S. and C. Percheski (2008). "Family Structure and the Reproduction of Inequalities." Annual Review of Sociology 34(1): 257-276.

Meier, K. J., J. Stewart and R. E. England (1989). Race, class, and education: The politics of second-generation discrimination, Univ of Wisconsin Press.

Mirowsky, J. and C. E. Ross (2015). "Education, Health, and the Default American Lifestyle." J Health Soc Behav 56(3): 297-306.

Montez, J. K. and M. D. Hayward (2014). "Cumulative childhood adversity, educational attainment, and active life expectancy among U.S. adults." Demography 51(2): 413-435.

Morgan, L. A. (1989). "“Economic Well-Being Following Marital Termination: A Comparison of Widowed and Divorced Women." " Journal of Family Issues 10(1): 86-101.

Oliver, M. L. and T. M. Shapiro (2006). Black wealth, white wealth: A new perspective on racial inequality, Taylor \& Francis.

Papke, L. E. and J. M. Wooldridge (1996). "Econometric methods for fractional response variables with an application to 401(k) plan participation." Journal of Applied Econometrics 11: $619-632$.

Pollack, C. E., S. Chideya, C. Cubbin, B. Williams, M. Dekker and P. Braveman (2007). "Should health studies measure wealth? A systematic review." Am J Prev Med 33(3): 250-264.

Pool, L. R., S. A. Burgard, B. L. Needham, M. R. Elliott, K. M. Langa and C. F. Mendes de Leon (2018). "Association of a Negative Wealth Shock With All-Cause Mortality in Middleaged and Older Adults in the United States." JAMA 319(13): 1341-1350.

Preston, S., P. Heuveline and M. Guillot (2001). Demography: Measuring and modeling population processes. Malden, MA, Blackwell.

Rendall, M. S., M. M. Weden, M. M. Favreault and H. Waldron (2011). "The protective effect of marriage for survival: a review and update." Demography 48(2): 481-506.

Reyes, A. M., M. Hardy and E. Pavalko (2018). "Race Differences in Linking Family Formation Transitions to Women's Mortality." Journal of Health and Social Behavior 59(2): 231-247.

Roxburgh, S. (2014). "Race, class, and gender differences in the marriage-health relationship." Race, Gender \& Class 21(3-4): 7-31.

Sbarra, D. A., R. W. Law and R. M. Portley (2011). "Divorce and Death: A Meta-Analysis and Research Agenda for Clinical, Social, and Health Psychology." Perspect Psychol Sci 6(5): 454-474.

Smock, P. J. (1993). "The Economic Costs of Marital Disruption for Young Women Over the Past Two Decades." Demography 30(3): 353-371.

Smock, P. J. (1994). "Gender and the Short-Run Economic Consequences of Marital Disruption." Social Forces 73(1): 243-262.

Smock, P. J., W. D. Manning and S. Gupta (1999). "The Effect of Marriage and Divorce on Women's Economic Well-Being." American Sociological Review 64(6): 794-812.

StataCorp (2019). Stata Statistical Software: Release 16. College Station, TX, StataCorp LP.

Tach, L. M. and A. Eads (2015). "Trends in the economic consequences of marital and cohabitation dissolution in the United States." Demography 52(2): 401-432.

Tomaskovic-Devey, D., M. Thomas and K. Johnson (2005). "Race and the accumulation of human capital across the career: A theoretical model and fixed-effects application." American Journal of Sociology 111(1): 58-89. 
Umberson, D. and M. B. Thomeer (2020). "Family Matters: Research on Family Ties and Health, 2010 to 2020." Journal of Marriage and Family 82(1): 404-419.

Umberson, D., K. Williams, P. A. Thomas, H. Liu and M. B. Thomeer (2014). "Race, gender, and chains of disadvantage: childhood adversity, social relationships, and health." Journal of Health and Social Behavior 55(1): 20-38.

Waite, L. J. (1995). "Does marriage matter?" Demography 32(4): 483-507.

Whisman, M. A., B. L. Robustelli and D. A. Sbarra (2016). "Marital disruption is associated with shorter salivary telomere length in a probability sample of older adults." Soc Sci Med 157: 60-67.

Wilkinson, L. R., K. F. Ferraro and S. A. Mustillo (2019). "Wealth in Middle and Later Life: Examining the Life Course Timing of Women's Health Limitations." The Gerontologist 59(5): 902-911.

Woldoff, R. A. and S. Ovadia (2009). "Not getting their money's worth: African-American disadvantages in converting income, wealth, and education into residential quality." Urban Affairs Review 45(1): 66-91.

Wolfe, J. D. (2015). "The Effects of Socioeconomic Status on Child and Adolescent Physical Health: An Organization and Systematic Comparison of Measures." Social Indicators Research 123(1): 39-58.

Wolfe, J. D., E. H. Baker and I. C. Scarinci (2019). "Wealth and Obesity Among US Adults Entering Midlife." Obesity.

Wolfe, J. D., S. Bauldry, M. A. Hardy and E. K. Pavalko (2018). "Multigenerational Attainment and Mortality Among Older Men: An Adjacent Generations Approach." Demographic Research 39: 719-752.

Wolfe, J. D., S. Bauldry, M. A. Hardy and E. K. Pavalko (2018). "Multigenerational Attainments, Racial Inequalities, and the Mortality of Silent Generation Women." Journal of Health and Social Behavior 59(3): 335-351.

Wooldridge, J. M. (2010). Econometric Analysis of Cross Section and Panel. Cambridge, MA, MIT Press.

Yilmazer, T., P. Babiarz and F. Liu (2015). "The impact of diminished housing wealth on health in the United States: Evidence from the Great Recession." Social science \& medicine 130: 234-241.

Zagorsky, J. L. (2005). "Marriage and divorce's impact on wealth." Journal of Sociology 41(4): 406-424. 
Figure 1: Predicted Differences Between Married and Divorced Women in Midlife Economic Resources with 95 Percent Confidence Intervals from Fractional Logistic Regression Models

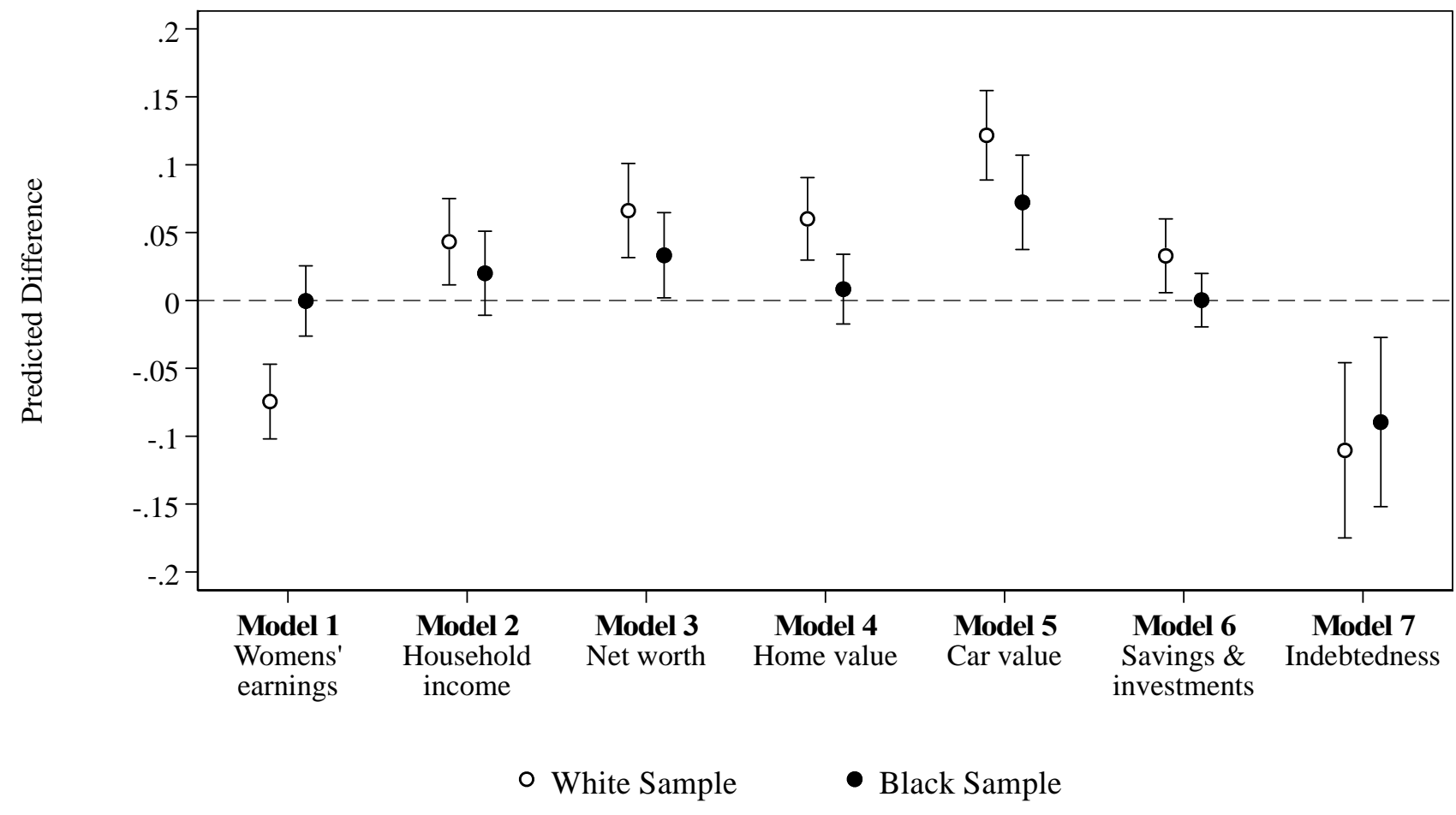

Note: Post-estimation values were calculated using parameter estimates from fractional logistic regression models predicting economic resources (see Table S1 in the Appendix S1). Positive values mean married women have, on average, higher rank wealth than divorced women. Differences with confidence intervals that overlap 0 are not significant. Differences were estimated while holding other variables at their observed values. 
Figure 2: Predicted Median Age of Death by Race and Marital Status with 95 Percent Confidence Intervals based on Gompertz Proportional Hazards Models

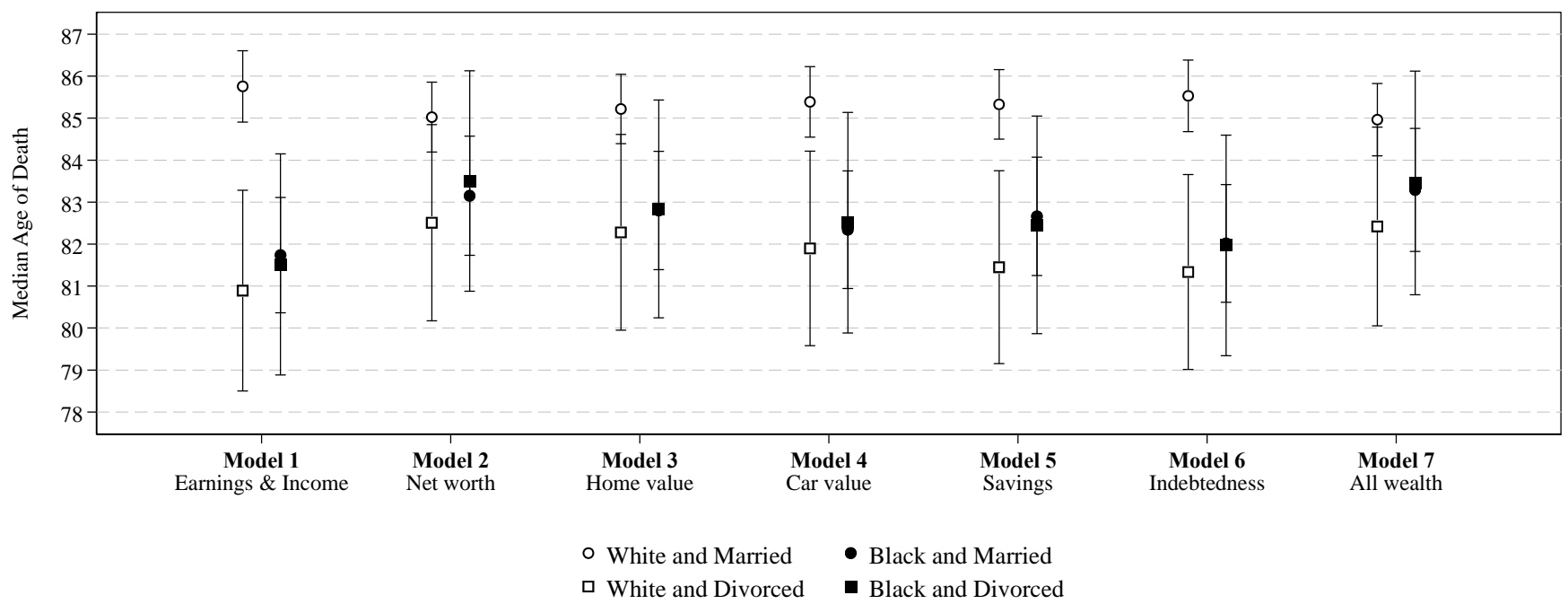

Note: Post-estimation values were calculated using parameter estimates from Gompertz proportional hazards models adjusting for economic resources in separate models (see Table S5 in the Appendix). 
Table 1. Averages or Proportions of Analysis Variables by Race $(N=4,668)$

\begin{tabular}{|c|c|c|c|c|}
\hline & & & $\begin{array}{c}\text { White Women } \\
\quad(N=3,383)\end{array}$ & $\begin{array}{c}\text { Black Women } \\
\quad(N=1,285)\end{array}$ \\
\hline & Min & Max & $\begin{array}{l}\text { Average or } \\
\text { Proportion }\end{array}$ & $\begin{array}{l}\text { Average or } \\
\text { Proportion }\end{array}$ \\
\hline Deceased by 2012 & 0 & 1 & .41 & .51 \\
\hline \multicolumn{5}{|l|}{ Marital Status } \\
\hline Continuously married & 0 & 1 & .72 & .53 \\
\hline Ever divorced & 0 & 1 & .11 & .22 \\
\hline Ever widowed & 0 & 1 & .15 & .26 \\
\hline Never married & 0 & 1 & .04 & .06 \\
\hline Ever remarried & 0 & 1 & .08 & .07 \\
\hline \multicolumn{5}{|l|}{ Midlife Economic Resources a } \\
\hline Personal earnings & 0 & 19.75 & 1.51 & 1.31 \\
\hline Family income & 0 & 22.46 & 5.06 & 2.60 \\
\hline Total net worth & -1.50 & 100 & 19.41 & 4.89 \\
\hline Home value & 0 & 100 & 14.86 & 5.05 \\
\hline Car value & 0 & 29.70 & 1.39 & 0.55 \\
\hline Savings and investments & 0 & 67.26 & 3.80 & 0.35 \\
\hline Indebtedness & 0 & 1 & .11 & .27 \\
\hline \multicolumn{5}{|l|}{ Controls } \\
\hline Age in 1967 & 30 & 44 & 37.26 & 37.29 \\
\hline Years of schooling & 0 & 18 & 11.39 & 9.81 \\
\hline Midlife employment & 0 & 1 & .75 & .75 \\
\hline Average household size $\mathrm{b}$ & 0 & 10.90 & 1.20 & 1.62 \\
\hline Health status in 1967 & 0 & 2 & & \\
\hline Excellent & & & .46 & .31 \\
\hline Good & & & .40 & .45 \\
\hline Fair or poor & & & .14 & .24 \\
\hline Parents' occupation & 0 & 3 & & \\
\hline Manual labor & & & .35 & .55 \\
\hline Farming & & & .20 & .34 \\
\hline Skilled & & & .27 & .11 \\
\hline White collar & & & .19 & -- \\
\hline Adolescent family structure & 0 & 2 & & \\
\hline Lived with both parents & & & .78 & .55 \\
\hline Lived with mother but not father & & & .13 & .23 \\
\hline Other family structure & & & .09 & .22 \\
\hline
\end{tabular}

a With the exception of debt, economic resources are in 2017 dollars and displayed in units of $\$ 10,000$. Due to extreme outliers, the maximum value is set to $\$ 1,000,000$.

b A zero value means that the respondent lived alone in every survey they were observed during midlife. 
Table 2: Hazard Ratios from Gompertz Proportional Hazards Models $(N=4,668)$

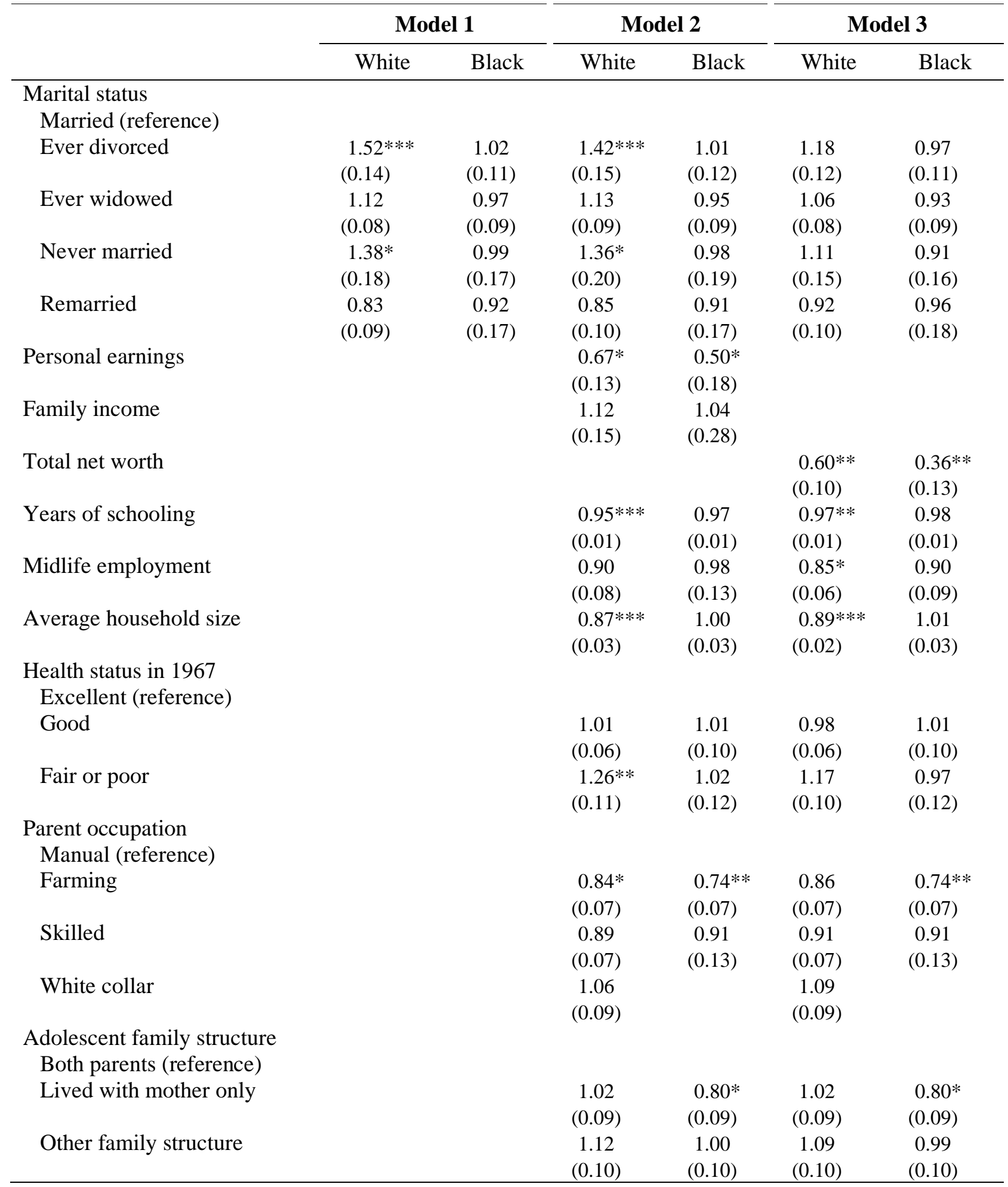

Note: Standard errors in parentheses, $* p<0.05, * * p<0.01, * * * p<0.001$ (two-tailed tests). Models 2 and 3 also controlled for age in 1967 and respondents' rank economic resources between the ages of 30 and 44 . 
Divorce, Economic Resources, and Survival

Table 3: Hazard Ratios from Gompertz Proportional Hazards Models, Considering the Components of Wealth Separately $(N=4,668)$

\begin{tabular}{|c|c|c|c|c|c|c|c|c|c|c|}
\hline & \multicolumn{2}{|c|}{ Model 1} & \multicolumn{2}{|c|}{ Model 2} & \multicolumn{2}{|c|}{ Model 3} & \multicolumn{2}{|c|}{ Model 4} & \multicolumn{2}{|c|}{ Model 5} \\
\hline & White & Black & White & Black & White & Black & White & Black & White & Black \\
\hline \multicolumn{11}{|l|}{ Marital status } \\
\hline \multicolumn{11}{|l|}{ Married (reference) } \\
\hline \multirow[t]{2}{*}{ Divorced } & $1.22 *$ & 0.99 & $1.29 *$ & 0.96 & $1.31 * *$ & 1.00 & $1.31 * *$ & 1.00 & $1.22 *$ & 0.96 \\
\hline & $(0.12)$ & $(0.11)$ & $(0.13)$ & $(0.11)$ & $(0.13)$ & $(0.11)$ & $(0.13)$ & $(0.11)$ & $(0.12)$ & $(0.11)$ \\
\hline \multirow[t]{2}{*}{ Ever widowed } & 1.05 & 0.95 & 1.06 & 0.92 & 1.10 & 0.95 & 1.08 & 0.96 & 1.04 & 0.93 \\
\hline & $(0.08)$ & $(0.09)$ & $(0.08)$ & $(0.09)$ & $(0.08)$ & $(0.09)$ & $(0.08)$ & $(0.09)$ & $(0.08)$ & $(0.09)$ \\
\hline \multirow[t]{2}{*}{ Never married } & 1.11 & 0.94 & 1.18 & 0.87 & 1.27 & 0.94 & 1.30 & 1.03 & 1.09 & 0.86 \\
\hline & $(0.16)$ & $(0.17)$ & $(0.17)$ & $(0.16)$ & $(0.17)$ & $(0.17)$ & $(0.18)$ & $(0.18)$ & $(0.16)$ & $(0.16)$ \\
\hline \multirow[t]{2}{*}{ Remarried } & 0.90 & 0.92 & 0.92 & 1.00 & 0.89 & 0.92 & 0.86 & 0.91 & 0.92 & 0.98 \\
\hline & $(0.10)$ & $(0.17)$ & $(0.10)$ & $(0.19)$ & $(0.10)$ & $(0.17)$ & $(0.10)$ & $(0.17)$ & $(0.10)$ & $(0.18)$ \\
\hline \multirow[t]{2}{*}{ Home value } & $0.62 * *$ & 0.84 & & & & & & & $0.66^{*}$ & \\
\hline & $(0.11)$ & $(0.29)$ & & & & & & & $(0.12)$ & \\
\hline Car value & & & $(0.11)$ & $(0.14)$ & & & & & $(0.15)$ & $(0.17)$ \\
\hline \multirow[t]{2}{*}{ Savings and investments } & & & & & 0.77 & $0.32 * *$ & & & & $0.41 *$ \\
\hline & & & & & $(0.11)$ & $(0.13)$ & & & & $(0.17)$ \\
\hline \multirow[t]{2}{*}{ Indebtedness } & & & & & & & 1.09 & 1.09 & & \\
\hline & & & & & & & $(0.11)$ & $(0.12)$ & & \\
\hline \multirow[t]{2}{*}{ Years of schooling } & $0.96 * * *$ & 0.98 & $0.95 * * *$ & 0.98 & $0.96 * * *$ & 0.98 & $0.95 * * *$ & 0.98 & $0.96 * *$ & 0.99 \\
\hline & $(0.01)$ & $(0.01)$ & $(0.01)$ & $(0.01)$ & $(0.01)$ & $(0.02)$ & $(0.01)$ & $(0.01)$ & $(0.01)$ & $(0.02)$ \\
\hline \multirow[t]{2}{*}{ Employed } & $0.84 *$ & 0.88 & $0.85 *$ & 0.91 & $0.85 *$ & 0.92 & $0.82 * *$ & 0.87 & $0.84 *$ & 0.93 \\
\hline & $(0.06)$ & $(0.09)$ & $(0.06)$ & $(0.09)$ & $(0.06)$ & $(0.10)$ & $(0.06)$ & $(0.09)$ & $(0.06)$ & $(0.10)$ \\
\hline \multirow[t]{2}{*}{ Average household size } & $0.89 * * *$ & 1.01 & $0.87 * * *$ & 1.01 & $0.88 * * *$ & 1.00 & $0.87 * * *$ & 1.00 & $0.89 * * *$ & 1.00 \\
\hline & $(0.02)$ & $(0.03)$ & $(0.02)$ & $(0.03)$ & $(0.02)$ & $(0.03)$ & $(0.02)$ & $(0.03)$ & $(0.03)$ & $(0.03)$ \\
\hline \multicolumn{11}{|l|}{ Health status in 1967} \\
\hline \multicolumn{11}{|l|}{ Excellent (reference) } \\
\hline \multirow[t]{2}{*}{ Fair or poor } & 1.19 & 0.99 & $1.21 *$ & 0.99 & $1.20 *$ & 1.01 & $1.27 * *$ & 1.03 & 1.18 & 0.99 \\
\hline & $(0.10)$ & $(0.12)$ & $(0.11)$ & $(0.12)$ & $(0.10)$ & $(0.12)$ & $(0.11)$ & $(0.13)$ & $(0.10)$ & $(0.12)$ \\
\hline
\end{tabular}


Divorce, Economic Resources, and Survival

Manual (reference)

$\begin{array}{lcccccccccc}\text { Farming } & 0.84^{*} & 0.75^{* *} & 0.85^{*} & 0.76^{* *} & 0.85^{*} & 0.74^{* *} & 0.85^{*} & 0.74^{* *} & 0.84^{*} & 0.75^{* *} \\ & (0.07) & (0.07) & (0.07) & (0.07) & (0.07) & (0.07) & (0.07) & (0.07) & (0.07) & (0.07) \\ \text { Skilled } & 0.92 & 0.92 & 0.90 & 0.92 & 0.90 & 0.92 & 0.88 & 0.93 & 0.92 & 0.92 \\ & (0.07) & (0.13) & (0.07) & (0.13) & (0.07) & (0.13) & (0.07) & (0.13) & (0.07) & (0.13) \\ \text { White collar } & 1.10 & & 1.08 & & 1.07 & & 1.04 & & 1.10 & (0.10) \\ & (0.09) & & (0.09) & & (0.09) & & (0.09) & & & \\ \text { Adolescent family structure } & & & & & & & & & & \\ \text { Both parents (reference) } & & & & & & & & & \\ \text { Lived with mother only } & 1.02 & 0.79^{*} & 1.03 & 0.78^{*} & 1.02 & 0.79^{*} & 1.02 & 0.82 & 1.02 & 0.78^{*} \\ & (0.09) & (0.09) & (0.09) & (0.09) & (0.09) & (0.09) & (0.09) & (0.09) & (0.09) & (0.09) \\ \text { Other family structure } & 1.10 & 1.00 & 1.11 & 0.99 & 1.12 & 1.00 & 1.11 & 1.00 & 1.10 & 0.99 \\ & (0.10) & (0.10) & (0.10) & (0.10) & (0.10) & (0.10) & (0.10) & (0.10) & (0.10) & (0.10)\end{array}$

Note: Standard errors in parentheses, $* p<0.05,{ }^{* *} p<0.01,{ }^{* * *} p<0.001$ (two-tailed tests). Models also controlled for age in 1967 and respondents' rank economic resources between the ages of 30 and 44. 